\title{
Study on the Fractal Characteristics of the Pomegranate Biotite Schist under Impact Loading
}

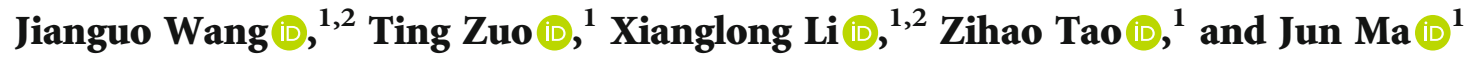 \\ ${ }^{1}$ Faculty of Land Resources Engineering, Kunming University of Science and Technology, Kunming, 650093 Yunnan, China \\ ${ }^{2}$ Yunnan Key Laboratory of Sino-German Blue Mining and Utilisation of Special Underground Space, Kunming, \\ 650093 Yunnan, China
}

Correspondence should be addressed to Ting Zuo; ztkust@163.com and Xianglong Li; 1xl00014002@163.com

Received 23 September 2021; Accepted 21 October 2021; Published 13 November 2021

Academic Editor: Haojie Lian

Copyright (c) 2021 Jianguo Wang et al. This is an open access article distributed under the Creative Commons Attribution License, which permits unrestricted use, distribution, and reproduction in any medium, provided the original work is properly cited.

In order to study the fractal characteristics of the pomegranate biotite schist under the effect of blasting loads, a one-dimensional SHPB impact test was carried out to test the dynamic compressive strength, damage morphology, fracture energy dissipation density, and other parameters of the rocks under different strain rates; besides, sieve tests were conducted to count the mass fractal characteristics of the crushed masses under different strain rates to calculate the fractal dimension of the crushed rock $D$. Finally, the relationships between fractal dimension and dynamic compressive strength, crushing characteristics, and energy dissipation characteristics were analysed. The results show that under different impact loads, the strain rate effect of the rock is significant and the dynamic compressive strength increases with the increasing strain rate, and they show a multiplicative power relationship. The higher the strain rate of the rock, the deeper the fragmentation and the higher the fractal dimension, and the fractal dimension and rock crushing energy density are multiplied by a power relationship. By performing the comparative analysis of the pomegranate biotite schist, a reasonable strain rate range of $78.75 \mathrm{~s}^{-1} \sim 82.51 \mathrm{~s}^{-1}$ and a reasonable crushing energy consumption density range of $0.78 \mathrm{~J} \cdot \mathrm{cm}^{-3} \sim 0.92 \mathrm{~J} \cdot \mathrm{cm}^{-3}$ were determined. This research provides a great reference for the analysis of dynamic crushing mechanism, crushing block size distribution, and crushing energy consumption of the roadway surrounding rock.

\section{Introduction}

The dynamic hazard is very frequent in the deep mining project $[1,2]$, and many scholars think that the fracture pattern is critical to studying the rock fractal in the mining, underground geotechnical engineering blasting, and other fields [3-5]. As one kind of typical rock in the deep mine roadway envelope, with fractal theory, the fractal evolution of crushed pomegranate biotite schist under impact loading was studied, and the relationship between its fractal dimension and the strain rate, dynamic compressive strength, average block size, and crushing energy dissipation density was also analysed, which is of great importance to blasting mining, hydraulic fracturing [6-8], and liquid $\mathrm{CO}_{2}$ fracturing [9].

The SHPB technique has been widely used for testing the dynamic properties of materials under the condition of high strain rates, such as rock [10-15]. Based on the fractal theory,
Tyler developed a mass fractal model for modelling the distribution of rock fracture bulkiness. Weng et al. [16] used SHPB equipment to conduct impact experiments on sandstones treated at different temperatures and studied their fractal characteristics and energy dissipation characteristics, respectively. Li et al. [17] analysed the relationship between the fractal dimension of the fracture angle of coal sections and the intact degree of coal rock under impact loading. Following the SHPB experimental setup, Huang et al. [18] studied the fractal fragmentation characteristics of sandstones with different water contents and obtained the relationship between fractal dimension and water content and energy consumption. By subjecting cyclic loading to sandstone specimens and combining fractal theory with energy consumption principles, $\mathrm{Hu}$ et al. [19] studied the crushing bulk and energy dissipation. Deng et al. [20] conducted impact loading tests on granite and sandstone and analysed dissipation characteristics with 


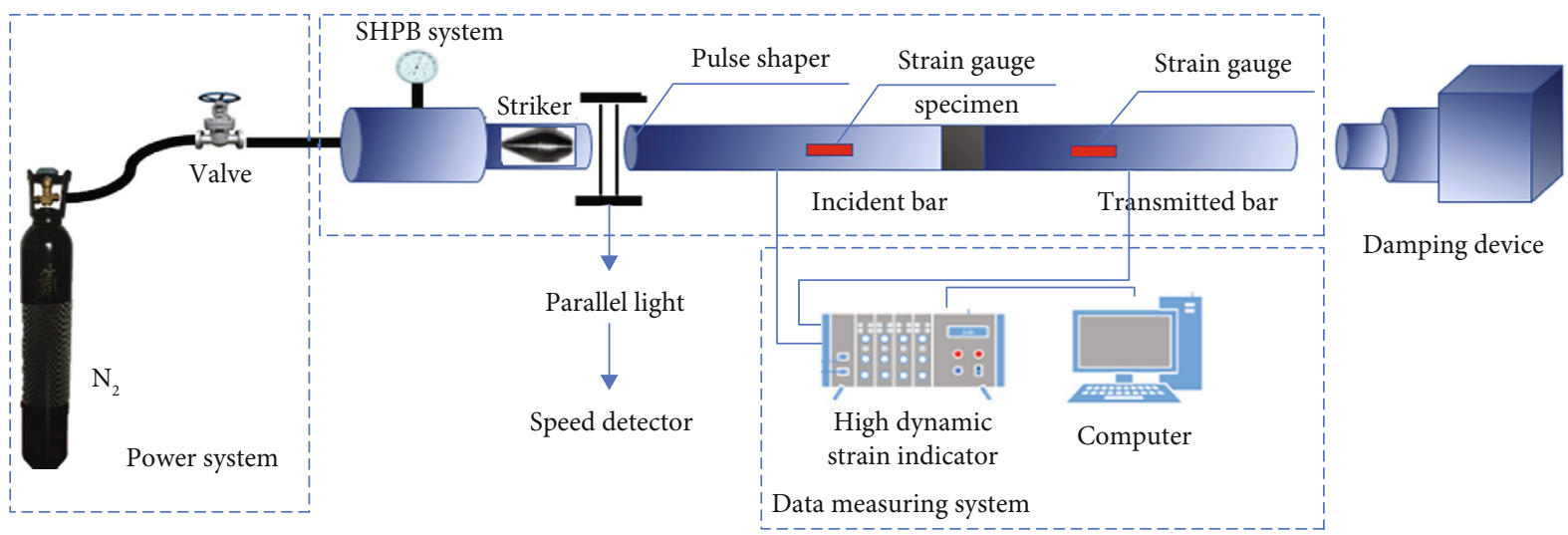

FIGURE 1: SHPB impact test system.

fractal theory. Zhao et al. [21] used the SHPB apparatus to test two types of rocks and analysed their relationships between the crushing characteristics and dynamic strength with fractal theory.

The present studies about the rock dynamics test mainly focus on the distribution of rock fragmentation bulk and energy dissipation; the relationships between fractal dimension and impact loading strain rate, average bulk, kinetic parameters, and energy density are rarely studied. Therefore, in this paper, SHPB kinetic tests and sieve tests were conducted on the pomegranate biotite schist, and the fractal dimension $D$ was calculated using the G-G-S fractal model.

\section{Test Preparation and Programme}

2.1. Experimental Procedure and Principles. As shown in Figure 1, a $\Phi 50 \mathrm{~mm}$ variable section Hopkinson pressure bar (SHPB) in the Rock Mechanics Laboratory of the Kunming University of Science and Technology is chosen, which consists of a loading system, a bullet, an incident bar, a transmission bar, a test signal collection system, and an energy absorption device. The length of the bullet is $0.4 \mathrm{~m}$, the length of the incident and the transmission bar is both $2.0 \mathrm{~m}$, the elastic modulus of the bar is $210 \mathrm{GPa}$, the metal bar is made of alloy steel with a density of $7.8 \mathrm{~g} / \mathrm{cm}^{3}$, and the longitudinal wave speed is $5190 \mathrm{~m} / \mathrm{s}$. Besides, the bar is powered by nitrogen pressurisation, and the laser velocimeter is used to measure the speed of the bar while applying impact loading. In order to eliminate the end effect and tip effect of the rock specimen, petroleum jelly is applied between the rock specimen and the incident and transmission bars to ensure that both ends of the specimen and the bar contact surfaces are smooth.

The SHPB test is designed based on the theory of the stress wave propagating in an elastic compression bar [22, 23], in which there are 2 basic assumptions, including the onedimensional elasticity and the uniform stress distribution. The cross section of the elastic compression bar is a plane during stress wave propagation, and the stress keeps constant. Because the two-wave method will cause errors while processing data, the three-wave method is usually adopted [24], by which the strain rate $\dot{\varepsilon}_{s}$, strain $\varepsilon$, and stress of the specimen $\sigma_{\mathrm{s}}$ can be expressed by

$$
\begin{gathered}
\dot{\varepsilon}_{\mathrm{s}}=\frac{C_{0}}{L_{\mathrm{s}}}\left[\varepsilon_{\mathrm{I}}(t)-\varepsilon_{\mathrm{R}}(t)-\varepsilon_{\mathrm{T}}(t)\right], \\
\varepsilon=\frac{C_{0}}{L_{\mathrm{s}}} \int_{0}^{t_{0}}\left[\varepsilon_{\mathrm{I}}(t)-\varepsilon_{\mathrm{R}}(t)-\varepsilon_{\mathrm{T}}(t)\right] d t, \\
\sigma_{\mathrm{s}}=\frac{E A}{2 A_{\mathrm{s}}}\left[\varepsilon_{\mathrm{I}}(t)-\varepsilon_{\mathrm{R}}(t)-\varepsilon_{\mathrm{T}}(t)\right],
\end{gathered}
$$

where $A_{\mathrm{s}}, A$ is the cross section area of the specimen and the compressional bar $\left(\mathrm{m}^{2}\right) ; C_{0}$ is the velocity of the elastic longitudinal wave of the compressional bar $(\mathrm{m} / \mathrm{s}) ; E$ is the elastic modulus of the bar $(\mathrm{GPa}) ; L_{\mathrm{s}}$ is the length of the specimen (m); $\varepsilon_{\mathrm{I}}, \varepsilon_{\mathrm{R}}$, and $\varepsilon_{\mathrm{T}}$ are the strains of the incident wave, reflected wave, and transmitted wave at a certain moment $t$; and $t$ is the propagation time of the stress wave in the bar (s).

In the process of the rock crushing, the incident energy $W_{\mathrm{I}}$, reflected energy $W_{\mathrm{R}}$, and transmitted energy $W_{\mathrm{T}}$ of the compressional bar can be calculated by the following equations.

$$
\left\{\begin{array}{l}
W_{\mathrm{I}}(t)=A E C_{0} \int_{0}^{t} \varepsilon_{\mathrm{I}}^{2}(t) d t \\
W_{\mathrm{R}}(t)=A E C_{0} \int \varepsilon_{\mathrm{R}}^{2}(t) d t \\
W_{\mathrm{T}}(t)=A E C_{0} \int \varepsilon_{\mathrm{T}}^{2}(t) d t .
\end{array}\right.
$$

After ignoring the energy loss in the propagation of the stress wave, the energy absorbed by the rock can be obtained as follows:

$$
W_{\mathrm{s}}=W_{\mathrm{I}}-\left(W_{\mathrm{R}}+W_{\mathrm{T}}\right) .
$$

If the crushing energy of the rock is supplied by the absorbed energy, the absorbed energy of the rock can be regarded as the crushing energy of the rock. To further reduce the influence of volumetric factors on the test results, the crushing energy density $\omega_{c p}$ is defined as follows for the crushing energy analysis. 
TABLE 1: Average values of physical parameters of specimens.

\begin{tabular}{lcccccccc}
\hline Specimen type & $\begin{array}{c}\text { Length } \\
(\mathrm{mm})\end{array}$ & $\begin{array}{c}\text { Diameter } \\
(\mathrm{mm})\end{array}$ & $\begin{array}{c}\text { Aspect } \\
\text { ratio }\end{array}$ & $\begin{array}{c}\text { Quality } \\
(\mathrm{g})\end{array}$ & $\begin{array}{c}\text { Density } \\
\left(\mathrm{kg} \cdot \mathrm{m}^{-3}\right)\end{array}$ & $\begin{array}{c}\text { Modulus of elasticity } \\
(\mathrm{GPa})\end{array}$ & $\begin{array}{c}\text { Poisson's } \\
\text { ratio }\end{array}$ & $\begin{array}{c}\text { Compressive } \\
\text { strength }(\mathrm{MPa})\end{array}$ \\
\hline $\begin{array}{l}\text { Pomegranate } \\
\text { biotite schist }\end{array}$ & 49.36 & 48.50 & 1.01 & 266.64 & 2943.36 & 106.80 & 0.31 & 59.82 \\
\hline
\end{tabular}

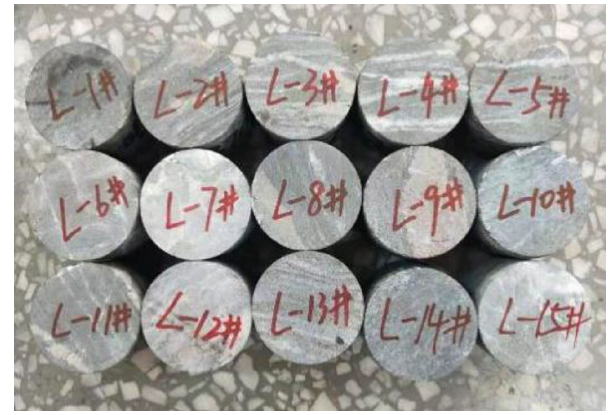

Figure 2: Pomegranate biotite schist.

$$
\omega_{c \mathrm{p}}=\frac{W_{\mathrm{s}}}{V}
$$

2.2. Specimen Preparation. The rock samples were taken from the Yuxi Mining Dahongshan Copper Mine, and they have high integrity and uniformity. The surface of the specimen is dark grey and has few apparent cracks. According to the requirements of the rock mechanics test, the nonparallelism at both ends of the specimen should be in the range of $-0.02 \mathrm{~mm} \sim+0.02 \mathrm{~mm}$, and the central axis of the specimen must be perpendicular to both ends of the specimen with an axial deviation of $-0.25^{\circ} \sim+0.25^{\circ}$. In order to reduce the influence of the end effect and tip effect on the test result, the rock specimen was processed into a cylinder with the size of 50 $\mathrm{mm} * 50 \mathrm{~mm}$. The initial physical parameters of the specimens are shown in Table 1, in which specimens of pomegranate biotite schist are numbered as $\mathrm{L}-1 \# \sim \mathrm{L}-15 \#$ as shown in Figure 2.

Before the test, the optimal impact pressure of $0.4 \mathrm{MPa}$ to $0.6 \mathrm{MPa}$ was determined with the test punches. For every impact pressure, more than 3 specimens were tested to guarantee the accuracy of the experimental results.

\section{Test Analysis of the Test Results}

3.1. Analysis of Fragmentation Patterns. After conducting impact tests on rock specimens under different impact pressures, seven sets of valid data were obtained, as shown in Table 2. The peak strain is defined as the strain value corresponding to the peak stress on the stress-strain curve.

Under the effect of impact loading, the crushing of rocks is actually a process of internal microscopic crack initiation, expansion, and accumulation, which finally leads to macroscopic fragmentation, and its damage pattern indicates the energy dissipation state and damage degree of rocks; besides, different impact velocities will induce the different fragmentation patterns of rocks, as shown in Figure 3.
It can be seen that the splitting damage occurred for the low strain rate, and the damage pattern gradually changed to edge spalling, core damage, block fragmentation, and crushing damage as the strain rate increased. From the perspective of fragmentation, as the impact velocity increased, the strain rate of the rock, the fine end of the fragmentation block, and the degree of fragmentation all increased, but the size of the fragmentation block decreased. This phenomenon can be explained as that when the rock specimen is subjected to impact loading at a low rate, the energy taken by the impact load is little, the internal microcracks will develop in an orderly direction, and a few cracks will develop and penetrate the rock specimen, inducing less broken pieces; with the increase in the impact loading rate, the energy subjected to the specimen increases, making the cracks within the specimen fully developed, which continuously expand and penetrate to form the apparent cracks, leading to more broken pieces, less size of the broken pieces, and high degree of fragmentation.

3.2. Analysis of Dynamic Strength Characteristics. The test results showed that the dynamic compressive strength of the pomegranate biotite schist was significantly affected by the strain rate. As shown in Figure 4, the dynamic compressive strength of the rock increased from $150.20 \mathrm{MPa}$ to 209.06 $\mathrm{MPa}$ as the strain rate increased from approximately $46.89 \mathrm{~s}^{-1}$ to $93.84 \mathrm{~s}^{-1}$; the relationship between them can be fitted by a multiplicative power function $\sigma_{f}=p \dot{\varepsilon}^{q}$ based on the research by Wang and $\mathrm{Li}[25,26]$. Under different strain rates, the significant change in dynamic compressive strength of rocks is known as the strain rate effect, which is a characteristic of the mechanical response of brittle materials due to change in the one-dimensional stress state. Moreover, as the strain rate increased, both the number of cracks within the rock and the required external energy increased; however, due to the extremely short duration of the impact loading, the required energy was not reached, so external energy can only be counteracted by increasing the stress. Therefore, the dynamic strength of the surrounding rock of the roadway should be taken into account to consider conditions such as roadway excavation blasting and mechanical dynamic loading, which will provide guidance for the optimisation of subsequent blasting parameters.

\subsection{Study on Fractal Characteristics of Rocks}

3.3.1. Calculation of Fragment Screening and Fractal Dimension. In order to quantitatively describe the fragmentation degree of the rock specimen, the distribution of the size of the broken pieces after the destruction was introduced to reflect the changing pattern of the destruction degree of the rock sample with the strain rate. The specimens were sieved using standard sieves of $0 \mathrm{~mm} \sim 25 \mathrm{~mm}$, and the fragments remaining 
TABLE 2: Characteristic parameters of rock fragmentation at different strain rates.

\begin{tabular}{lccccccc}
\hline $\begin{array}{l}\text { Specimen } \\
\text { number }\end{array}$ & $\begin{array}{c}\text { Impact pressure } \\
(\mathrm{MPa})\end{array}$ & $\begin{array}{c}\text { Impact velocity } \\
\left(\mathrm{m} \cdot \mathrm{s}^{-1}\right)\end{array}$ & $\begin{array}{c}\text { Strain rate } \\
\left(\mathrm{s}^{-1}\right)\end{array}$ & $\begin{array}{c}\text { Dynamic compressive } \\
\text { strength }(\mathrm{MPa})\end{array}$ & $\begin{array}{c}\text { Peak } \\
\text { strain }\end{array}$ & $\begin{array}{c}\text { Absorbed } \\
\text { energy }(\mathrm{J})\end{array}$ & $\begin{array}{c}\text { Crushing energy } \\
\text { density }\left(\mathrm{J} \cdot \mathrm{cm}^{-3}\right)\end{array}$ \\
\hline L-5\# & 0.40 & 10.13 & 46.89 & 150.20 & 0.0108 & 51.53 & 0.57 \\
L-4\# & 0.45 & 10.86 & 59.69 & 152.79 & 0.0096 & 57.09 & 0.63 \\
L-3\# & 0.45 & 12.09 & 70.21 & 163.41 & 0.0101 & 66.95 & 0.74 \\
L-7\# & 0.50 & 12.55 & 78.75 & 177.19 & 0.0112 & 71.21 & 0.78 \\
L-8\# & 0.55 & 13.63 & 82.51 & 197.10 & 0.0126 & 81.23 & 0.89 \\
L-10\# & 0.58 & 14.54 & 90.63 & 198.20 & 0.0115 & 83.31 & 0.92 \\
L-14\# & 0.60 & 15.04 & 93.84 & 209.06 & 0.0142 & 89.16 & 0.98 \\
\hline
\end{tabular}

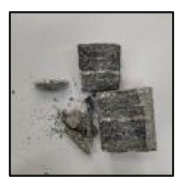

$10.13(\mathrm{~m} / \mathrm{s})$

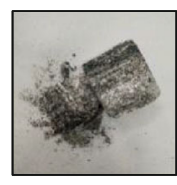

$10.86(\mathrm{~m} / \mathrm{s})$

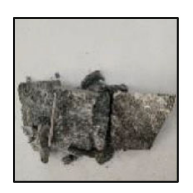

$12.09(\mathrm{~m} / \mathrm{s})$

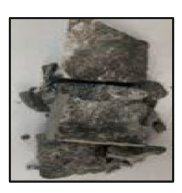

$12.55(\mathrm{~m} / \mathrm{s})$

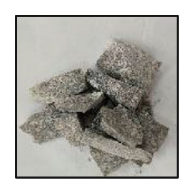

$13.63(\mathrm{~m} / \mathrm{s})$

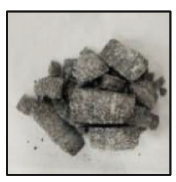

$14.54(\mathrm{~m} / \mathrm{s})$

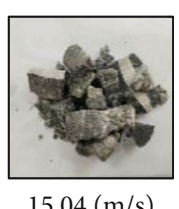

$15.04(\mathrm{~m} / \mathrm{s})$

FIGURE 3: Damage pattern of pomegranate biotite schist at different impact velocities.

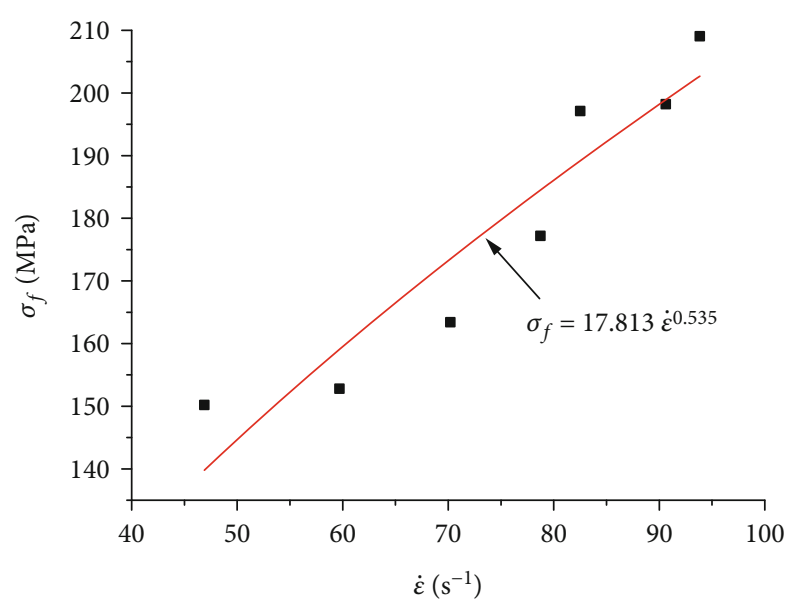

- Pomegranate biotite schist

- Fitting curve

Figure 4: Dynamic compressive strength versus strain rate for pomegranate biotite schist.

above the sieve holes were weighed and converted into the percentage of fragments of rock (Table 3); thus, the fragmentation distribution curve of pomegranate biotite schist can be obtained and is shown in Figure 5.

According to Figure 5, after the pomegranate biotite schist specimen was subjected to conventional uniaxial impact loading, the percentage of fragments whose size was larger than $25 \mathrm{~mm}$ decreased from $66.78 \%$ to $31.28 \%$, and the strain rate increased from $46.89 \mathrm{~s}^{-1}$ to $93.84 \mathrm{~s}^{-1}$. The change in the block size distribution of fragments whose size was less than $20 \mathrm{~mm}$ and below was relatively gentle.

Besides the particle size distribution, the fractal dimension is also an important indicator to characterise the fractal characteristics of the rock, and it increases with the degree of fragmentation of the specimen. The G-G-S model is now commonly used to describe the fractal bulkiness of fine-grained ends [27].

$$
Y=\left(\frac{r}{r_{m}}\right)^{b}
$$

where $b$ is the corresponding regression coefficient. Based on the relationship between mass and frequency, the fracture fragmentation distribution of the rock sample can be obtained:

$$
Y=\frac{M_{\mathrm{r}}}{M_{\mathrm{t}}}=\left(\frac{r}{r_{\mathrm{m}}}\right)^{3-D} \text {, }
$$

where $M_{\mathrm{r}}$ is the mass of rock fragments with the particle size less than $r, M_{\mathrm{t}}$ is the total mass of rock fragments, $r$ is the particle size of rock fragmentation, and $r_{\mathrm{m}}$ is the maximum particle size. By taking the logarithm of both sides in equation (6),

$$
\lg Y=\lg \left[\frac{M_{\mathrm{r}}}{M_{\mathrm{t}}}\right]=(3-D) \lg \left(\frac{r}{r_{\mathrm{m}}}\right) .
$$

In a new coordinate system of $\lg \left[M_{\mathrm{r}} / M_{\mathrm{t}}\right]-\lg r$, the slope of the line can be represented as $3-D$. The $\lg \left[M_{\mathrm{r}} / M_{\mathrm{t}}\right]-\lg x$ curves describing the distribution of fragments of pomegranate biotite schist are shown in Figure 6.

It can be seen that the slope of the particle size characteristic curve decreased with the strain rate, indicating that the mass of the end of the fine of the crushed pomegranate nepheline gneiss gradually increased, and the crushing degree became higher. The average block size and fractal dimension of the fragmented pomegranate nepheline gneiss are shown in Table 4 , and the large correlation coefficient $R$ indicates that under impact loading, the distribution of block size is consistent with the fractal pattern.

3.3.2. Fractal Dimension versus Strain Rate and Mean Bulkiness. As shown in Figure 6, the double logarithmic function showed high linearity, indicating that the block distribution of the rock after fragmentation has a self-similarity or fractal character. This phenomenon can be explained as that the aggregation 
TABLE 3: Table of impact test sieve sizes corresponding to weighing masses.

\begin{tabular}{|c|c|c|c|c|c|c|c|c|c|c|c|}
\hline $\begin{array}{l}\text { Sizes }(\mathrm{mm}) \\
\text { Mass }(\mathrm{g}) \\
\text { Strain rate }\left(\mathrm{s}^{-1}\right)\end{array}$ & 0 & 0.3 & 0.5 & 1.0 & 2.5 & 5.0 & 10.0 & 15.0 & 20.0 & 25.0 & Total mass \\
\hline 46.89 & 0.24 & 0.22 & 0.42 & 1.74 & 2.34 & 11.78 & 16.07 & 20.66 & 28.94 & 173.32 & 255.73 \\
\hline 51.28 & 0.59 & 0.34 & 0.56 & 2.45 & 2.47 & 10.43 & 27.55 & 44.20 & 28.80 & 149.44 & 266.83 \\
\hline 59.69 & 0.70 & 1.22 & 1.29 & 3.38 & 3.78 & 17.89 & 31.26 & 40.41 & 28.09 & 149.44 & 277.46 \\
\hline 70.21 & 1.11 & 1.67 & 1.50 & 3.66 & 3.98 & 32.92 & 48.00 & 21.64 & 32.92 & 115.63 & 263.03 \\
\hline 76.37 & 3.24 & 1.89 & 1.63 & 7.74 & 6.96 & 30.45 & 27.41 & 45.08 & 36.04 & 103.34 & 263.78 \\
\hline 78.75 & 1.45 & 4.55 & 4.54 & 8.73 & 6.56 & 28.06 & 34.85 & 42.58 & 33.54 & 98.55 & 263.41 \\
\hline 82.51 & 2.32 & 3.78 & 3.82 & 12.38 & 7.86 & 33.18 & 46.56 & 36.71 & 21.70 & 105.23 & 273.54 \\
\hline 90.63 & 3.54 & 5.68 & 4.65 & 14.35 & 20.04 & 39.42 & 35.21 & 25.08 & 32.34 & 87.35 & 267.66 \\
\hline 92.28 & 4.78 & 3.02 & 8.65 & 18.34 & 21.09 & 31.87 & 36.21 & 23.21 & 24.56 & 92.50 & 264.23 \\
\hline 93.84 & 4.44 & 5.39 & 5.31 & 17.90 & 22.13 & 38.52 & 43.52 & 30.28 & 17.97 & 84.41 & 269.87 \\
\hline
\end{tabular}

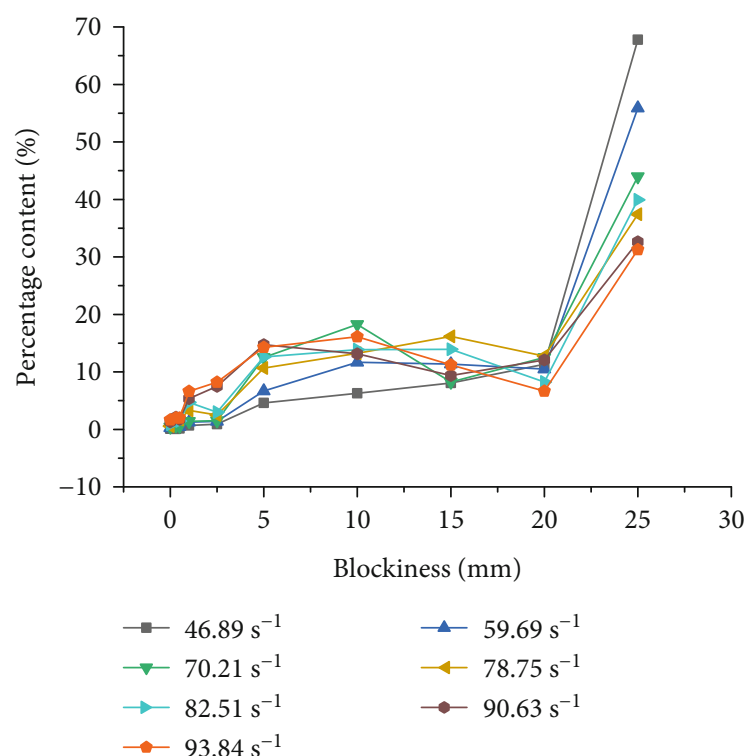

FIGURE 5: Distribution of fragmentation bulkiness of pomegranate biotite schist at different strain rates.

of small internal cracks lead to the macroscopic destruction of the rock, and the small fracture evolves from smaller microfractures. This self-similarity inevitably leads to the selfsimilar characteristics of the final block distribution. Therefore, the fractal dimension can be used to describe rock fragmentation quantitatively.

According to Figures 7 and 8, the fractal dimension $D$ can be related to the strain rate and average block size, respectively. The average block size is defined as the block size whose cumulative percentage is less than $50 \%$, as expressed in

$$
d_{\mathrm{s}}=\frac{\sum r_{i} d_{i}}{\sum r_{i}}
$$

where $d_{\mathrm{s}}$ is the average block size of rock fragments less than sieve diameters $r_{i}$ and $d_{i}$ is the mass percentage of rock fragments.

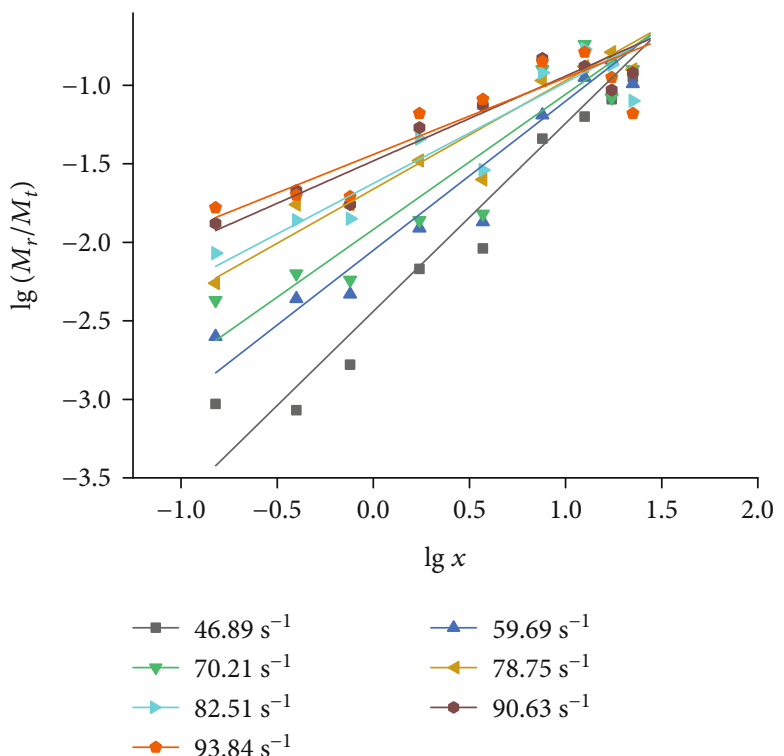

Figure 6: Curves for the distribution of fractional bulkiness of pomegranate biotite schist.

This parameter can quantify the distribution of bulkiness and the variation of fragmentation of the rock under different dynamic loads. Figures 7 and 8 show a strong correlation between the fractal dimension and strain rate $\dot{\varepsilon}$ and average block size $d_{s}$, in which the fractal dimension $D$ increased from 1.80 to 2.51 and the average block size decreased from $23.78 \mathrm{~mm}$ to $15.60 \mathrm{~mm}$, indicating that the fractal block size distribution of the pomegranate biotite schist is self-similar and has obvious fractal characteristics.

3.3.3. Fractal Dimension and Crushing Energy Consumption Density. Based on the research of Hong et al. [28], the relationship between the fractal dimension of the rock $D$ and the dissipation density of crushing energy $\omega_{c p}$ was fitted by a multiplicative power function in Figure 9.

As shown in Figure 9, the fractal dimension of the rock $D$ exponentially increased with crushing energy density $\omega_{c p}$ , and the higher crushing energy density indicates that more 
TABLE 4: Crushing bulkiness statistics of pomegranate biotite schist under impact loading.

\begin{tabular}{lccccccc}
\hline Specimen number & L-5\# & L-4\# & L-3\# & L-7\# & L-8\# & L-10\# & L-14\# \\
\hline Average crushing size $(\mathrm{mm})$ & 23.78 & 21.76 & 19.65 & 18.61 & 18.16 & 16.48 & 15.60 \\
Fractal dimension $D$ & 1.80 & 2.05 & 2.14 & 2.31 & 2.36 & 2.46 \\
Correlation coefficient $R$ & 0.92 & 0.91 & 0.86 & 0.91 & 0.85 & 0.87 & 0.77 \\
\hline
\end{tabular}

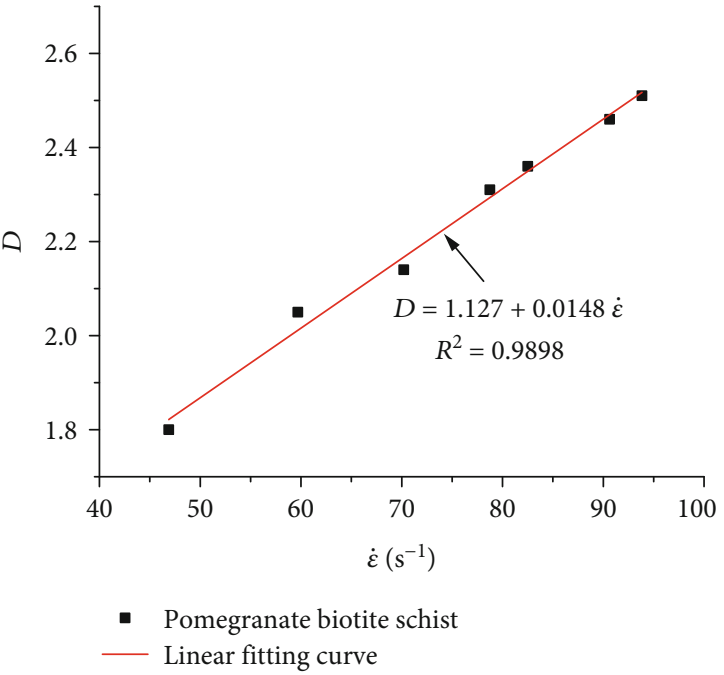

FIGURE 7: Fractal dimension versus strain rate for pomegranate biotite schist.

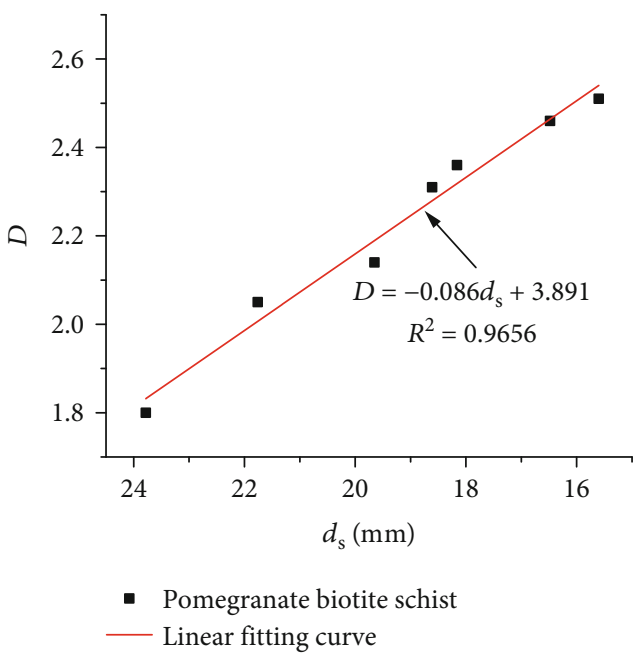

FIGURE 8: Relation between fractal dimension and average block size for pomegranate biotite schist.

energy is required to crush the rock, and the more severe the rock crushing, the more fine-grained the fragments and the higher the fractal dimension $D$.

3.4. Study of Rock Crushing Effects and Energy Dissipation. In summary, an increase in the strain rate makes the effective crushing bulk of the rock gradually migrate towards the fine-grain end, enhancing the crushing effect. However, an increase in the crushing effect means an increase in crushing energy density. Therefore, a reasonable range of

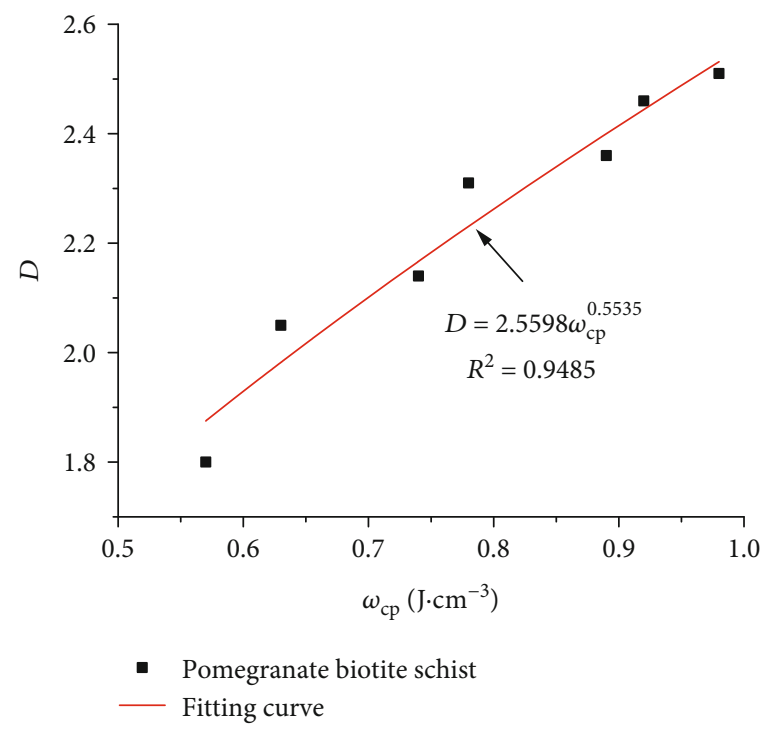

FIGURE 9: Fractal dimension of pomegranate biotite schist versus crushing energy density.

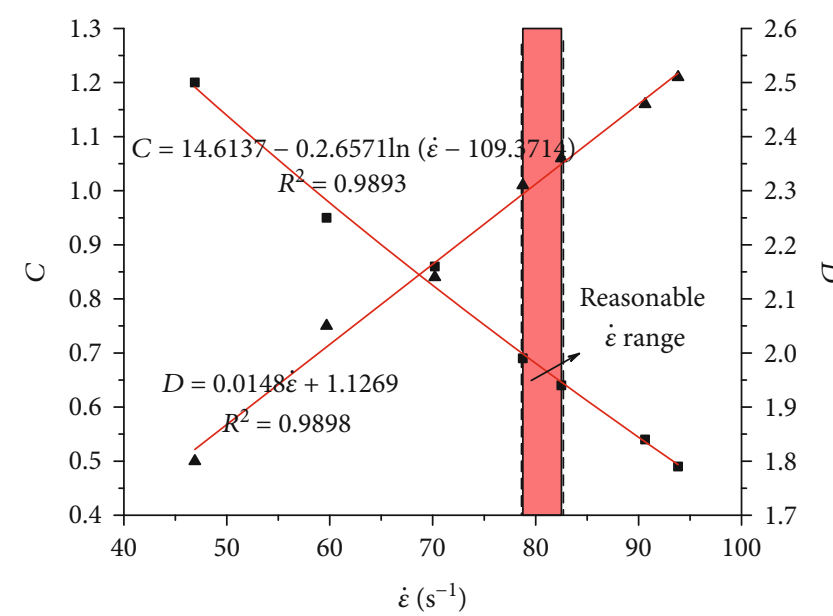

- Blockiness distribution coefficient $C$

- Fractal dimension $D$

FIGURE 10: Relationship diagram for determining the range of reasonable strain rates.

the strain rate and crushing energy density is of great practical importance to enhance the crushing effect and reduce energy consumption.

In Figure 6, the particle size characteristic curve is characterised by the distribution of rock crushing bulk, and the slope of the curve is defined as the bulk distribution 


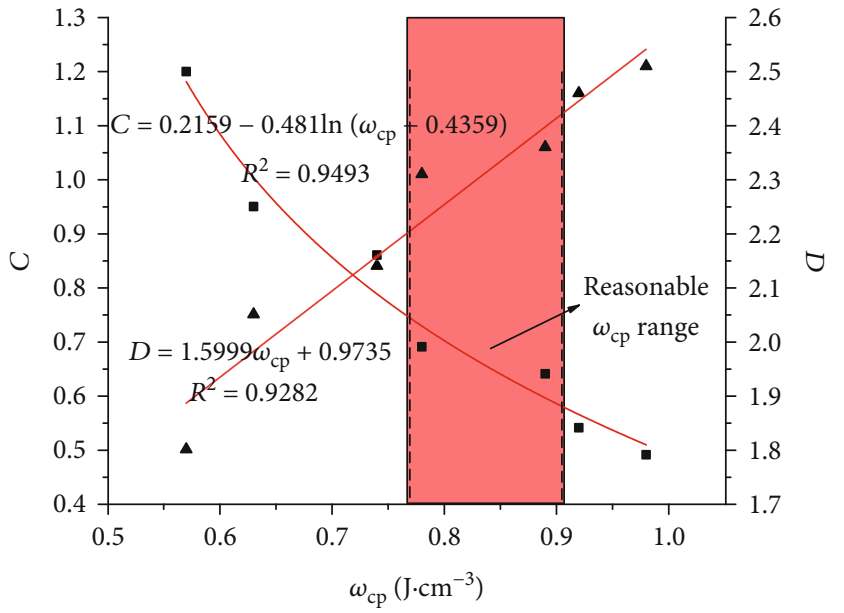

- Blockiness distribution coefficient $C$

- Fractal dimension $D$

FIGURE 11: Relationship diagram for determining the range of reasonable crushing energy consumption densities.

coefficient $C$. Figures 10 and 11, respectively, show the relationship between the fractal dimension $D$ and the strain rate and the relationship between the bulk distribution coefficient $C$ and crushing energy consumption density.

It can be seen from Figure 10 that the slope of the curve changed fast and the decreasing rate started to increase when $\dot{\varepsilon}$ was close to $59.69 \mathrm{~s}^{-1}$; after $\dot{\varepsilon}$ exceeds $82.51 \mathrm{~s}^{-1}$, the decreasing rate of the curve decreased. Therefore, in order to achieve a better crushing effect, the $\dot{\varepsilon}$ should be controlled in the range of $59.69 \mathrm{~s}^{-1} \sim 82.51 \mathrm{~s}^{-1}$, and the corresponding range of the fractal dimension curve was $70.21 \mathrm{~s}^{-1} \sim 90.63 \mathrm{~s}^{-1}$. Similarly, in Figure 11, the dissipation density of crushing energy of two curves can be determined to be in the range of $0.74 \mathrm{~J} \cdot \mathrm{cm}^{-3} \sim 0.92 \mathrm{~J} \cdot \mathrm{cm}^{-3}$ and $0.78 \mathrm{~J} \cdot \mathrm{cm}^{-3} \sim 0.98 \mathrm{~J} \cdot \mathrm{cm}^{-3}$, respectively.

According to the relationship between the strain rate and crushing energy density in Table 2 , it can be indicated that the reasonable strain rate range should be $78.75 \mathrm{~s}^{-1} \sim 82.51 \mathrm{~s}^{-1}$ to achieve rock crushing and the reasonable crushing energy density range should be $0.78 \mathrm{~J} \cdot \mathrm{cm}^{-3} \sim 0.92 \mathrm{~J} \cdot \mathrm{cm}^{-3}$ (the dashed line range in Figures 10 and 11).

\section{Conclusion}

In this paper, the typical tunnel envelope rock, pomegranate biotite schist, was selected to carry out SHPB rock dynamic mechanical tests, and rock fragmentation characteristics under different strain rates, strength indexes, and energy parameters were obtained to establish the relationship between fractal dimension and these parameters. This research provides a reference for further study of the dynamic mechanical properties of pomegranate biotite schist in deep mining and provides guidance for the optimisation design of blasting parameters for underground mine tunnelling. The main conclusions can be drawn as follows.

(1) The fragmentation distribution of pomegranate biotite schist is significantly affected by the strain rate under the effect of impact loading. As the strain rate increases, the degree of fragmentation decreases; the fine ends of the fragments increase with the fragmentation degree. Besides, the dynamic compressive strength increases with the strain rate, showing a power relationship

(2) The fractal dimension $D$ can quantify the fracture characteristics of the rock, it increases as the strain rate increases, and when the strain rate ranges from $46.89 \mathrm{~s}^{-1}$ to $93.84 \mathrm{~s}^{-1}$, the fractal dimension $D$ of pomegranate biotite schist is $1.80 \sim 2.51$

(3) The fractal dimension $D$ can quantify the fractal energy dissipation characteristics of a rock, and it increases with the fractal energy density $\omega_{c p}$ in a multiplicative power relationship

(4) The reasonable strain rate range to achieve good crushing effectiveness and reduce crushing energy consumption for pomegranate biotite schist is $78.75 \mathrm{~s}^{-1} \sim 82.51 \mathrm{~s}$ ${ }^{1}$, and the reasonable crushing energy consumption density range should be $0.78 \mathrm{~J} \cdot \mathrm{cm}^{-3} \sim 0.92 \mathrm{~J} \cdot \mathrm{cm}^{-3}$

\section{Data Availability}

The data used to support the findings of this study are included in the article.

\section{Conflicts of Interest}

The authors declare that they have no conflicts of interest.

\section{Authors' Contributions}

J.W. and T.Z. were responsible for the conceptualisation, methodology, validation, data curation, visualisation, and original draft preparation. Experimental guidance and data analysis were performed by X.L. Theoretical analysis was conducted by Z.T. and J.M. Formal analysis and review and editing of the manuscript were performed by all the authors. All authors have read and agreed to the published version of the manuscript. Ting Zuo is the co-first author.

\section{Acknowledgments}

This study was financially supported by the National Natural Science Foundation of China (No. 51934003), and its support is gratefully appreciated.

\section{References}

[1] J. Yang, T. J. Min, B. H. Liu, K. K. Chen, and L. Yang, "Research progress on disasters and prevention in deeping mining," Science Technology and Engineering, vol. 20, no. 36, pp. 14767-14776, 2020.

[2] H. P. Xie, "Research review of the state key research development program of China: deep rock mechanics and mining theory," Journal of China Coal Society, vol. 44, no. 5, pp. 1283-1305, 2019.

[3] R. S. Yang, P. Xu, C. Z. Jing, J. P. Fan, S. Z. Fang, and H. Zhang, "Experimental study on deformation failure and dynamic 
tensile strength of layered sandstone under impact load," Journal of China Coal Society, vol. 44, no. 7, pp. 2039-2048, 2019.

[4] H. Wu, B. Dai, L. Cheng, R. Lu, G. Y. Zhao, and W. Z. Liang, "Experimental study of dynamic mechanical response and energy dissipation of rock having a circular opening under impact loading," Mining, Metallurgy \& Exploration, vol. 38, no. 2, pp. 1111-1124, 2021.

[5] H. Wu and D. Ma, "Fracture response and mechanisms of brittle rock with different numbers of openings under uniaxial loading," Geomechanics and Engineering, vol. 25, no. 6, pp. 481-493, 2021.

[6] Z. Liu, J. Yang, L. Yang, X. Ren, X. Peng, and H. Lian, "Experimental study on the influencing factors of hydraulic fracture initiation from prefabricated crack tips," Engineering Fracture Mechanics, vol. 250, article 107790, 2021.

[7] L. Chen, Z. Wang, X. Peng, J. Yang, P. Wu, and H. Lian, "Modeling pressurized fracture propagation with the isogeometric BEM," Geomechanics and Geophysics for Geo-Energy and Geo-Resources, vol. 7, no. 3, 2021.

[8] Z. Liu, X. Ren, X. Lin, H. Lian, L. Yang, and J. Yang, "Effects of confining stresses, pre-crack inclination angles and injection rates: observations from large-scale true triaxial and hydraulic fracturing tests in laboratory," Rock Mechanics and Rock Engineering., vol. 53, no. 4, pp. 1991-2000, 2020.

[9] J. Yang, H. Lian, and L. Li, "Fracturing in coals with different fluids: an experimental comparison between water, liquid $\mathrm{CO}_{2}$, and supercritical $\mathrm{CO}_{2}$," Scientific Reports, vol. 10, no. 1, 2020.

[10] M. M. He, Z. Q. Zhang, J. Zheng, F. F. Chen, and N. Li, “A new perspective on the constant mi of the Hoek-Brown failure criterion and a new model for determining the residual strength of rock," Rock Mechanics and Rock Engineering, vol. 53, no. 9, pp. 3953-3967, 2020.

[11] J. G. Wang, Y. Liu, and K. G. Li, "Dynamic characteristics of deep dolomite under one-dimensional static and dynamic loads," Journal of The Institution of Engineers (India): Series $A$, vol. 101, no. 1, pp. 49-56, 2020.

[12] M. M. He, Z. Q. Zhang, J. W. Zhu, N. Li, G. Li, and Y. S. Chen, "Correlation between the rockburst proneness and friction characteristics of rock materials and a new method for rockburst proneness prediction: field demonstration," Journal of Petroleum Science and Engineering, vol. 205, p. 108997, 2021.

[13] M. M. He, Z. Q. Zhang, and N. Li, “Deep convolutional neural network-based method for strength parameter prediction of jointed rock mass using drilling logging data," International Journal of Geomechanics, vol. 21, no. 7, 2021.

[14] Y. B. Wang, Y. Yang, Y. T. Zhang, and J. G. Wang, "Dynamic mechanical properties of coals subject to the low temperatureimpact load coupling effect," Scientific reports, vol. 9, no. 1, 2019.

[15] R. S. Yang, S. Z. Fang, W. Y. Li, G. H. Wei, Q. Li, and S. F. Liang, "Temperature effects on dynamic compressive behavior of siliceous sandstone," Arabian journal of geosciences, vol. 13, no. $10,2020$.

[16] L. Weng, Z. J. Wu, Q. S. Liu, and Z. Y. Wang, "Energy dissipation and dynamic fragmentation of dry and water-saturated siltstones under sub-zero temperatures," Engineering Fracture Mechanics, vol. 220, article 106659, 2019.

[17] C. J. Li, Y. Xu, P. Y. Chen, H. L. Li, and P. J. Lou, "Dynamic mechanical properties and fragment fractal characteristics of fractured coal-rock-like combined bodies in split Hopkinson pressure bar tests," Natural Resources Research, 2020.

[18] M. Huang, J. Y. Qiu, J. W. Zhan, Y. Su, and X. D. Xie, "Fractal law of weak-weathered argillaceous siltstone with different water contents subjected to SHPB impact crushing," Journal of Engineering Geology, vol. 24, no. 4, pp. 597-603, 2016.

[19] H. Hu, Q. Q. Zheng, X. Gao et al., "Fracture characteristics and geometric fractal of damaged sandstone under impact load," Shock and Vibration, vol. 2020, Article ID 6617197, 2020.

[20] Y. Deng, M. Chen, Y. Jin, and D. W. Zou, "Theoretical analysis and experimental research on the energy dissipation of rock crushing based on fractal theory," Journal of Natural Gas Science and Engineering, vol. 33, pp. 231-239, 2016.

[21] H. H. Zhao, C. Liu, J. Zhang, and L. Ge, "Breakage behavior of gravel rock particles under impact force," Computational Particle Mechanics, 2021.

[22] K. W. Xia, S. Wang, Y. Xu, R. Chen, and B. B. Wu, “Advances in experimental studies for deep rock dynamics," Chinese Journal of Rock Mechanics and Engineering, vol. 40, no. 3, pp. 448475, 2021.

[23] Z. L. Wang and Z. T. Lu, "Application of SHPB in experimental teaching of rock dynamics," Research and Exploration in Laboratory, vol. 33, no. 1, pp. 214-216, 2014.

[24] L. Song and S. S. Hu, "Two-wave and three-wave method in SHPB data processing," Explosion and Shock Waves, vol. 25, no. 4, pp. 368-373, 2005.

[25] J. J. Zhu, X. B. Li, F. Q. Gong, S. M. Wang, and W. He, "Experimental test and damage characteristics of sandstone under uniaxial impact compressive loads," Journal of Centra South University (Science and Technology), vol. 43, no. 7, pp. 27012707, 2012.

[26] B. Wang and X. B. Li, "Mesomechanics analysis of static compressive strength and dynamic compressive strength of watersaturated rock under uniaxial load," Explosion and Shock Waves, vol. 32, no. 4, pp. 423-431, 2012.

[27] L. Xie, Q. H. Li, and S. L. Xu, "Experimental study on fractal of steam free reactive powder concrete under impact load," Engineering Mechanics, vol. 38, no. 3, pp. 169-180, 2021.

[28] L. Hong, X. B. Li, and C. D. Ma, "Study on size effect of rock dynamic strength and strain rate sensitivity," Chinese Journal of Rock Mechanics and Engineering, vol. 27, no. 3, pp. 526533, 2008. 